\title{
A comparison of exposure assessment approaches: lung cancer and occupational asbestos exposure in a population-based case-control study
}

\author{
Jill S Hardt, ${ }_{1}^{1}$ Roel Vermeulen, ${ }^{2}$ Susan Peters, ${ }^{2,3}$ Hans Kromhout, ${ }^{2}$ \\ John R McLaughlin, ${ }^{1,4}$ Paul A Demers ${ }^{1}$
}

${ }^{1}$ Occupational Cancer Research

Centre, Cancer Care Ontario,

Toronto, Ontario, Canada

${ }^{2}$ Environmental Epidemiology

Division, Institute for Risk

Assessment Sciences, Utrecht

University, Utrecht, The Netherlands

${ }^{3}$ Epidemiology Group, Centre for Medical Research,

University of Western Australia, Perth, Australia

${ }^{4}$ Public Health Ontario, and Lunenfeld-Tannenbaum Research Institute, Toronto, Ontario, Canada

\section{Correspondence to}

Jill S Hardt, Occupational

Cancer Research Centre,

Cancer Care Ontario, 505

University Avenue, 17th Floor,

Toronto, ON, Canada M5G 1X3;

jill.hardt@occupationalcancer.ca

Received 15 July 2013

Revised 5 November 2013

Accepted 24 November 2013

Published Online First

11 December 2013
To cite: Hardt JS,

Vermeulen R, Peters $S$, et al.

Occup Environ Med

2014;71:282-288.

\section{ABSTRACT}

Objectives In attempts to overcome the limitations of self-reported data in occupational health research, jobexposure matrices, which assign exposure by occupation, have emerged as an objective approach for assessing occupational exposures. On the basis of a lung cancer case-control study conducted in the Greater Toronto Area, 1997-2002, assessment of occupational exposure to asbestos was compared using self-reports and a general population job-exposure matrix (DOM-JEM). Methods Cases and frequency matched controls provided life-time job histories and self-reported exposures to potential lung carcinogens including asbestos through a detailed questionnaire. Exposure to asbestos was also assigned to each job by linking occupational histories with DOM-JEM. Agreement in classification of exposed and unexposed jobs according to self-reports and DOM-JEM was evaluated using Cohen's $\kappa$. Risks for lung cancer were estimated using unconditional logistic regression for each exposure assessment approach.

Results The prevalence of occupational asbestos exposure was greater when based on DOM-JEM than when based on self-reports. Agreement in classifying exposure to jobs between the two assessment approaches was poor. The risk of lung cancer was not elevated among workers who self-reported asbestos exposure, whereas workers considered exposed on the basis of DOM-JEM were almost twice as likely as unexposed workers to be diagnosed with lung cancer (OR 1.9, 95\% Cl 1.3 to 2.7).

Conclusions It is generally assumed by epidemiologists that self-reported exposure assessments result in inflated risk estimates. In this study, self-reports found no association with a well-established risk factor, whereas a high-quality job-exposure matrix revealed relative risk estimates that are more consistent with previous findings.

\section{INTRODUCTION}

Obtaining accurate retrospective information about occupational exposures can be a challenge because of the extent and variable quality of available data. In occupational epidemiology, case-by-case expert assessment has emerged as the preferred approach for retrospective exposure assessment for population-based studies. ${ }^{1}$ By reviewing work histories on a case-by-case basis, experts including occupational hygienists can take into account subject-specific differences such as types of industry

\section{What this paper adds}

- Studies examining health impacts of occupational carcinogens often collect exposure information directly from workers through questionnaires, but workers' inability to accurately assess, recall and report exposures to specific carcinogenic agents can obscure the ability to detect associations between exposures and adverse health outcomes.

- Job-exposure matrices, developed by exposure scientists and which assign exposure by occupation, are an efficient alternative for assessing occupational exposures.

- A comparison of self-reports and a job-exposure matrix assessment of occupational asbestos exposure revealed poor agreement in classifying exposed and unexposed workers in a lung cancer case-control study conducted in the Greater Toronto Area, 1997-2002.

- Only assessment using the job-exposure matrix identified the expected associations between occupational asbestos exposure and increased lung cancer risk, which indicated that the job-exposure matrix assessment approach was more accurate in classifying exposure than self-reports.

- This study demonstrates the significant challenge posed by retrospective assessments of occupational exposures and highlights the diverging adequateness of assessment approaches to support effective risk identification.

and local differences in production, safety measures and variations over time. However, this approach is time and labour intensive, and validity and reliability are dependent on the exposures being assessed, assessor expertise, and the clarity of information. Less time-consuming and expensive methods include applying a job-exposure matrix (JEM) or assessing exposure using self-reports. The latter option is the least costly and does not require the involvement of exposure experts, although the ability of workers to accurately assess, recall and report exposure to specific agents is a potential limitation. ${ }^{2}$ The complexity of an individual's occupational history, duration of employment, and the 
length of recall period have been found to influence the validity and reliability of self-reports. ${ }^{1}$ Recall bias is a particular threat in case-control studies, since cases are thought to be more likely than controls to recall prior exposures. ${ }^{3}$ Despite these limitations, Teschke et $a l^{1}$ concluded that, in comparison with quantitative exposure measurements, case-by-case expert assessments performed only slightly better than self-reports in case-control studies.

JEMs, first developed in the 1980 s, are a relatively inexpensive alternative approach to retrospective occupational exposure assessment. ${ }^{4-7}$ With occupations and/or industries on one axis and exposure agents on the other, the cells of the matrix indicate the presence, intensity and/or probability of exposure to a particular substance in a specific job. ${ }^{7}$ JEMs are based on expert judgement of occupational hygienists, published literature, and/or databases of direct measures. Although it first requires applying standardised occupation and/or industry codes to job histories, the use of existing JEMs to retrospectively assess occupational exposures is much less resource intensive than case-by-case expert assessment. ${ }^{9}{ }^{10}$ In contrast with selfreports, exposure assessments based on JEMs are not affected by potential differential recall between cases and controls. ${ }^{11}$ However, JEMs do not take into account local conditions and potential differences in exposure among individuals with the same job title.

DOM-JEM was recently developed for application in population-based studies. ${ }^{12}$ It can be used to assess exposure to a selection of agents for each five-digit International Standard Classification of Occupations 1968 (ISCO-68) code. DOM-JEM does not include a time axis, and exposure levels are based on a combination of intensity and probability of exposure within a job. ${ }^{13}$ It has previously been applied in studies of lung cancer risk and exposure to asbestos, diesel motor exhaust, chromium, nickel, organic dust, polycyclic aromatic hydrocarbons and silica. $^{12-17}$ In the Netherlands Cohort Study, ${ }^{13}$ DOM-JEM showed the highest level of agreement with case-by-case expert assessment ( $\kappa$ 0.29) compared with two other JEMs (FINJEM and Asbestos JEM).

Recently, Brenner et $a l^{17}$ studied the risk of lung cancer associated with selected occupational exposures based on selfreports in a case-control study in the Greater Toronto Area, but no association was found with asbestos (OR 1.1, 95\% CI 0.6 to 2.0). We hypothesise that the null result reported by Brenner et al could be due to limitations of self-reported exposure, which may have contributed to exposure misclassification, obscuring exposure-disease associations. Although the association between lung cancer and asbestos exposure is well known, ${ }^{18}$ a wide range of risk estimates have been reported in occupational studies. ${ }^{19}$ Some of this heterogeneity can be attributed to true differences resulting from variation in circumstances of exposure such as fibre type, processes, regulations and practices with respect to personal protective equipment and the work environment, and temporality and duration of exposure. However, on the basis of a recent review and meta-analysis, Lenters et $a l^{19}$ concluded that differences across studies in lung cancer risk estimates associated with asbestos exposure were at least partly explained by variations in exposure assessment quality. Furthermore, this meta-analysis revealed that, when the analyses were limited to studies with higher-quality exposure assessment methods, lung cancer risk estimates increased. Previous comparisons of self-reported occupational exposure with JEMs found that exposure tended to be more prevalent according to self-reports. ${ }^{4}{ }^{20-22}$ Asbestos exposure was previously found to be associated with increased lung cancer risk when based on self-reports, but not when based on JEM assessment. $^{20}$

Our study used data from the study reported by Brenner et $a l^{17}$ to measure agreement between approaches in classifying jobs as exposed or unexposed, and to examine the characteristics of individuals and jobs where assessments were discordant. Furthermore, this study examined the risk of lung cancer associated with occupational asbestos exposure according to selfreports versus DOM-JEM and to determine the risk of lung cancer according to duration of exposure for each approach.

\section{MATERIALS AND METHODS \\ Study design}

Cases of incident cancer of the trachea, bronchus or lung diagnosed among men and women between 20 and 84 years old were identified between 1997 and 2002 through four major tertiary care hospitals in metropolitan Toronto. ${ }^{17}$ Cancer diagnoses were classified according to the International classification of diseases for oncology, 3rd edition. ${ }^{23}$ Cancer-free populationbased controls randomly selected from property tax assessment files $(n=425)$ and hospital controls selected from patients at Mount Sinai Hospital Family Medicine Clinic, Toronto $(n=523)$ were frequency matched to cases based on age, sex and ethnicity. Study design was previously described by Brenner et al. ${ }^{17}$

\section{Data collection and exposure assessment}

Lifetime work histories and demographic information were collected through a detailed questionnaire that was administered in person or by phone. Participants were asked about workplace exposure to potential lung carcinogens (including asbestos, paints and/or solvents), welding equipment, pesticides, grain elevator dust, wood dust and smoke, soot or exhaust. Self-reported asbestos exposure was assessed with the question: 'In any of your jobs have you ever worked with asbestos?' On the basis of work histories, each job was coded according to ISCO-68 and the International standard industrial classification of all economic activities, Rev.2. For stratified analyses, jobs were grouped according to ISCO-68 codes as follows: Professional/ technical, 010-199; Construction, 870-874, 950-959; Blue collar excluding construction, 700-862, 880-949, 960-999; Other, 200-649 (this group includes administrative, managerial, clerical, sales, service, agricultural and related workers). Occupational histories were linked, blinded to case status, with a general population JEM (DOM-JEM) according to five-digit ISCO-68 codes to assign no, low or high exposure to asbestos to each job based on a combination of intensity and probability of exposure in a job. DOM-JEM was created by three occupational exposure experts (HK, RV and SP) independently of information from any study population and has been described previously. ${ }^{12}$ Classification of exposed and unexposed jobs was determined according to each method. Each study participant was evaluated using a dichotomous exposure indicator (never/ ever) according to each assessment approach. Duration of exposure was defined as the number of years employed in a job classified as ever exposed according to each approach. Each year of part-time employment was considered to be 0.5 years. On the basis of DOM-JEM assessment, individuals were further categorised using an ordinal intensity variable (no/only low/ever high).

\section{Statistical analysis}

Differences in demographics, smoking history and exposure between cases and controls were assessed using $\chi^{2}$ and Student's $t$ tests. Chance-corrected agreement in exposure assessment 
(exposed or unexposed) according to self-reports and DOM-JEM was evaluated using Cohen's $\kappa$ for cases and controls by sex, occupation group, duration of employment, and years since job end. Cohen's $\kappa$ statistics were interpreted as follows: $<0.4$, poor; $0.4-0.75$, fair to good; $>0.75$, excellent agreement. $^{24}$ Characteristics of study participants (and jobs) for whom there was discordance in exposure assessments were compared with those with concordant assessments using $\chi^{2}$ and $t$ tests. Lung cancer risks were estimated using unconditional logistic regression adjusted for age group ( $<35$ years, 35-44 years, 45-54 years, 55-64 years, 65-74, $>75$ years), sex and cumulative tobacco consumption (cigarette pack-years). Risks associated with duration of exposure using predefined categories (1-10 years, >10 years) were also estimated. Analyses were stratified by source of controls. A 10-year lag was introduced from the date of diagnosis for cases or the date of interview for controls. Analyses were conducted using SAS V.9.2.

\section{RESULTS}

\section{Subject characteristics}

Participation was $62 \%$ for cases, $60 \%$ for population controls, and $84 \%$ for hospital controls. Of the 716 eligible cases, 116 refused to participate and 155 died before study entry and/or complete data collection. Owing to missing work history information, 20 cases and 38 controls were excluded, resulting in a sample of 425 cases and 910 controls. Nearly 85\% $(n=1139)$ of participants reported two or more jobs in their lifetime work history. A total of 5083 work history observations were collected from 1335 individuals. Of these, 4406 (87\%) were fulltime jobs. Cases were significantly older and less educated than controls. Compared with controls, a greater proportion of cases were employed in blue collar jobs and were current or former smokers. The distribution of demographic and smoking variables for cases and controls is detailed in Brenner et al. ${ }^{17}$

\section{Exposure prevalence}

According to self-reports, $82(6 \%)$ study participants had been exposed to asbestos in one or more jobs. Overall, more than twice as many were considered exposed according to DOM-JEM (194, 15\%) (table 1). The difference between DOM-JEM assessment and self-reports was twofold for workers employed in construction and fourfold for workers employed in jobs classified as 'blue collar excluding construction'. Differences in assigned exposure between DOM-JEM and selfreports were greater for jobs worked less recently, with nearly eight times more workers considered exposed according to DOM-JEM compared with self-reports when considering jobs worked before 1940, and more than 12 times for jobs that ended during the 1940s. Most individuals classified as exposed according to DOM-JEM were in the 'only low' group based on exposure probability and intensity $(n=176,13 \%)$. Only 18 $(1 \%)$ individuals were ever employed in a job in the 'high' exposure group. While the likelihood of self-reporting exposure did not differ significantly between cases and controls (7\% vs $6 \%, \mathrm{p}=0.23$ ), cases were much more likely than controls to be classified as ever exposed according to DOM-JEM (23\% vs $11 \%, \mathrm{p}<0.0001)$. The proportion self-reporting exposure to asbestos was similar between population $(6 \%)$ and hospital controls (5\%), while prevalence of exposure according to DOM-JEM was greater among population controls $(13 \%$ vs 9\%).

\section{Agreement in exposure assessment}

Agreement was poor between self-reports and DOM-JEM in assigning exposure (exposed or unexposed) to each job (к 0.19) (table 1). When restricted to only the longest job held by each individual, the estimate of agreement was unchanged (results not shown). Agreement was higher among controls than cases ( $\kappa$ 0.25 vs 0.12 ), and did not vary by source of controls. This higher agreement observed in controls compared with cases was consistent for all analyses of agreement (results not shown). The greatest agreement between the assessment approaches was observed for jobs in construction ( $\kappa$ 0.30). When stratified by the last decade in which an individual was employed in a particular job, there was a weak positive trend of increasing agreement associated with recentness of employment.

\section{Characteristics of individuals where discordance between assessments occurred}

Discordance in exposure assessments for at least one job occurred among $17 \%$ of study participants for whom assessments according to both approaches were available (table 2). Of those with discordant observations, 22\% over-reported and $78 \%$ under-reported exposure relative to DOM-JEM in one or more jobs. Discordance was more likely to occur among cases than controls (26\% vs $13 \%)$. Population controls were slightly more likely than hospital controls to under-report exposure relative to DOM-JEM (11\% vs $8 \%$ ). Likelihood of discordance was not statistically significantly associated with age for overreporting $(p=0.21)$, but approached statistical significance for under-reporting $(p=0.06)$ relative to DOM-JEM. The large majority of discordant assessments were observed among older study participants, which parallels the results indicating an increase in agreement between assessments for more recently worked jobs (table 1). Education was not a determinant of agreement between approaches, but those with the least education were most likely to under-report exposure (24\%) (table 2). Likelihood of discordance was significantly associated with occupation group $(p<0.0001)$. Discordance in assessments occurred often for jobs in the 'blue collar excluding construction' group, with under-reporting more common than overreporting (36\% vs 5\%). Under-reporting was most common for jobs in 'construction'. Of the 69 individuals who were ever employed in construction, over $40 \%$ under-reported exposure to asbestos relative to DOM-JEM in one or more construction jobs. Under-reporting occurred most often in jobs where individuals were employed for 10 years or fewer. The proportion of study participants who under-reported exposure appeared to decline with recentness of employment.

\section{Lung cancer risk}

Self-reported asbestos exposure was not associated with an increased risk of lung cancer (OR 0.9, 95\% CI 0.5 to 1.6) (table 3). However, when assessed using DOM-JEM, a nearly twofold increase in risk was observed (OR 1.9, 95\% CI 1.3 to 2.7). Compared with those not exposed according to DOM-JEM, those ever employed in a job classified as 'high' exposure were at slightly greater risk of lung cancer than those employed only in jobs classified as 'low' exposure (OR 2.3, 95\% CI 0.8 to 6.5 vs OR 1.9, 95\% CI 1.2 to 2.6). Individuals employed for more than 10 years in one or more occupations classified as asbestos-exposed according to DOM-JEM were at significantly greater risk of lung cancer than those exposed for 10 years or fewer compared with the unexposed group (OR 2.6, 95\% CI 1.5 to 4.5 vs OR $1.5,95 \%$ CI 0.9 to 2.4 ). 
Table 1 Numbers and percentages of workers ever exposed to asbestos, and agreement (Cohen's $\kappa$ ) between self-reports and DOM-JEM assessment approach, Greater Toronto Area, Ontario, 1997-2001

\begin{tabular}{|c|c|c|c|c|c|c|}
\hline & \multirow[b]{2}{*}{ No of workers } & \multicolumn{2}{|c|}{ Self-reports } & \multicolumn{2}{|c|}{ DOM-JEM } & \multirow[b]{2}{*}{ к } \\
\hline & & $\mathrm{n}$ & $\%$ & $\mathrm{n}$ & $\% *$ & \\
\hline Overall $†$ & 1335 & 82 & 6.1 & 194 & 14.8 & 0.19 \\
\hline \multicolumn{7}{|l|}{ Level of exposure } \\
\hline Low & & & & 176 & 13.4 & 0.16 \\
\hline High§ & & & & 18 & 1.4 & 0.22 \\
\hline \multicolumn{7}{|l|}{ Lung cancer status } \\
\hline Cases & 425 & 31 & 7.3 & 97 & 23.2 & 0.12 \\
\hline Controls & 910 & 51 & 5.6 & 97 & 10.9 & 0.25 \\
\hline Population controls & 405 & 24 & 5.9 & 54 & 13.3 & 0.26 \\
\hline Hospital controls & 505 & 27 & 5.3 & 43 & 8.5 & 0.24 \\
\hline \multicolumn{7}{|l|}{ Sex } \\
\hline Men & 580 & 68 & 11.7 & 151 & 26.3 & 0.20 \\
\hline Women & 755 & 14 & 1.9 & 43 & 5.8 & 0.05 \\
\hline \multicolumn{7}{|l|}{ Occupation group } \\
\hline Professional/technical & 600 & 15 & 2.5 & 9 & 1.5 & 0.07 \\
\hline Construction & 69 & 17 & 24.6 & 37 & 53.6 & 0.30 \\
\hline Blue collar excluding construction & 399 & 37 & 9.7 & 156 & 39.1 & 0.06 \\
\hline Other** & 972 & 16 & 1.6 & 19 & 2.0 & 0.15 \\
\hline \multicolumn{7}{|l|}{ Duration of employment (years) $+\dagger$} \\
\hline $1-10$ & 1180 & 47 & 4.0 & 150 & 12.9 & 0.18 \\
\hline $11-20$ & 482 & 21 & 4.4 & 46 & 9.5 & 0.22 \\
\hline$>20$ & 338 & 18 & 5.3 & 34 & 10.3 & 0.16 \\
\hline \multicolumn{7}{|l|}{ Decade of job termination $\ddagger$} \\
\hline$<1940$ & 111 & 2 & 1.8 & 12 & 13.8 & 0.10 \\
\hline 1940-1949 & 143 & 2 & 1.4 & 24 & 17.6 & 0.11 \\
\hline 1950-1959 & 278 & 9 & 3.2 & 34 & 12.3 & 0.05 \\
\hline 1960-1969 & 385 & 17 & 4.4 & 44 & 11.6 & 0.22 \\
\hline 1970-1979 & 512 & 17 & 3.3 & 42 & 8.3 & 0.24 \\
\hline 1980-1989 & 693 & 24 & 3.5 & 59 & 8.7 & 0.28 \\
\hline$>1990$ & 1035 & 27 & 2.6 & 74 & 7.3 & 0.15 \\
\hline
\end{tabular}

${ }^{*}$ Denominators used to calculate proportions exposed differ for self-reports and DOM-JEM assessment because of incomplete occupation information.

†No DOM-JEM assessments available for 22 individuals because of incomplete occupation information.

¥Agreement between classification of 'exposed' versus 'unexposed' according to self-reports and 'ever employed in a job with low exposure and never employed in a job with high exposure' versus 'unexposed' according to DOM-JEM.

$\S$ Agreement between classification of 'exposed' versus 'unexposed' according to self-reports and 'ever employed in a job with high exposure' versus 'unexposed' according to

DOM-JEM.

IIndividuals may be counted in more than one category.

**Includes administrative, managerial, clerical, sales, service, agricultural and related workers.

†tDuration of employment missing for 49 individuals; individuals may be counted in more than one category.

$\ddagger \ddagger$ Year of job termination missing for 94 individuals; individuals may be counted in more than one category.

DOM-JEM, general population job-exposure matrix.

Risk estimates did not differ significantly when restricted to population or hospital controls (results not shown).

\section{DISCUSSION}

This study compared two retrospective occupational exposure assessment approaches, self-reports and DOM-JEM, in a Toronto-area lung cancer case-control study. The identification of risks to support interventions to protect workers depends on the accuracy of exposure assessment approaches. Self-reports are commonly used to assess occupational exposure, but perception of exposure among individuals and the correspondence between potential and actual exposure are not well understood. There is strong evidence that workers are neither aware ${ }^{2}$ nor able to accurately report ${ }^{25} 26$ occupational exposure to agents when compared with more direct measures of exposure. ${ }^{27}$ This study found substantial differences in prevalence of asbestos exposure and associated risks of lung cancer when exposure was assessed by both self-reports and DOM-JEM.
First, this study found that DOM-JEM estimated a greater prevalence of asbestos exposure than self-reports. Previous studies examining asbestos exposure and lung cancer risk similarly found that JEMs identified a greater prevalence of exposure than self-reports. ${ }^{12} 2829$ In our study, prevalence of asbestos exposure was nearly 2.5 times greater according to DOM-JEM compared with self-reports. While cases and controls were equally likely to report occupational exposure to asbestos, exposure based on DOM-JEM was significantly greater among cases. This elevated exposure prevalence among cases was expected if asbestos exposure were indeed associated with excess lung cancer risk in this study population.

Second, agreement was remarkably poor between assessments, which is consistent with previous comparisons of selfreports and JEM assessments. ${ }^{28}{ }^{30}$ As might be expected, ${ }^{26}$ cases were more likely than controls to over-report exposure relative to DOM-JEM, which may be evidence of differential recall bias. This differential recall bias is usually assumed to 
Table 2 Characteristics of individuals where there was discordance between self-reports relative to DOM-JEM assessment approach, Greater Toronto Area, Ontario, 1997-2001

\begin{tabular}{|c|c|c|c|c|c|c|c|}
\hline & & \multicolumn{2}{|c|}{$\begin{array}{l}\text { Discordant Group } \\
1^{*} \\
\text { Over-report }\end{array}$} & \multirow[b]{2}{*}{ p Value } & \multicolumn{2}{|c|}{$\begin{array}{l}\text { Discordant Group } \\
2 \dagger \\
\text { Under-report }\end{array}$} & \multirow[b]{2}{*}{ p Value } \\
\hline & & $\mathbf{n}$ & $\%$ & & $\mathbf{n}$ & $\%$ & \\
\hline \multicolumn{8}{|l|}{ No of workers } \\
\hline Overall & 1313 & 49 & 3.7 & & 174 & 13.3 & \\
\hline Cases & 419 & 20 & 4.8 & $<0.05$ & 90 & 21.5 & $<0.05$ \\
\hline Controls & 894 & 29 & 3.2 & & 84 & 9.4 & \\
\hline Population controls & 397 & 10 & 2.5 & & 45 & 11.3 & \\
\hline Hospital controls & 497 & 19 & 3.8 & & 39 & 7.8 & \\
\hline \multicolumn{8}{|l|}{ Sex } \\
\hline Male & 574 & 37 & 6.4 & $<0.0001$ & 133 & 23.2 & $<0.05$ \\
\hline Female & 739 & 12 & 1.6 & & 41 & 5.5 & \\
\hline \multicolumn{8}{|l|}{ Age (years) } \\
\hline$<35$ & 124 & 1 & 0.8 & 0.21 & 9 & 7.3 & 0.06 \\
\hline $35-44$ & 189 & 8 & 4.2 & & 17 & 9.0 & \\
\hline $45-54$ & 230 & 4 & 1.7 & & 22 & 9.6 & \\
\hline $55-64$ & 275 & 14 & 5.1 & & 36 & 13.1 & \\
\hline $65-74$ & 339 & 8 & 2.4 & & 30 & 8.8 & \\
\hline $75+$ & 156 & 14 & 9.0 & & 60 & 38.5 & \\
\hline \multicolumn{8}{|l|}{ Education (years) } \\
\hline$<8$ & 235 & 7 & 3.0 & 0.92 & 58 & 24.7 & 0.36 \\
\hline $8-12$ & 548 & 24 & 4.4 & & 81 & 14.8 & \\
\hline $13+$ & 507 & 18 & 3.6 & & 32 & 6.3 & \\
\hline \multicolumn{8}{|l|}{ No of jobs } \\
\hline \multicolumn{8}{|l|}{ Occupation } \\
\hline Professional/technical & 600 & 14 & 2.3 & $<0.0001$ & 8 & 1.3 & $<0.0001$ \\
\hline Construction & 69 & 3 & 4.3 & & 28 & 40.6 & \\
\hline Blue collar excluding construction & 399 & 20 & 5.0 & & 145 & 36.3 & \\
\hline Other§ & 972 & 13 & 1.3 & & 16 & 1.6 & \\
\hline \multicolumn{8}{|l|}{ Duration of employment (years) } \\
\hline $1-10$ & 1137 & 24 & 2.1 & $<0.0001$ & 136 & 12.0 & 0.40 \\
\hline $11-20$ & 439 & 13 & 3.0 & & 40 & 9.1 & \\
\hline$>20$ & 296 & 12 & 4.1 & & 28 & 9.5 & \\
\hline \multicolumn{8}{|l|}{ Decade of job termination } \\
\hline$<1940$ & 87 & 0 & 0.0 & 0.34 & 11 & 12.6 & 0.16 \\
\hline 1940-1949 & 136 & 0 & 0.0 & & 22 & 16.2 & \\
\hline 1950-1959 & 276 & 7 & 2.5 & & 32 & 11.6 & \\
\hline 1960-1969 & 379 & 9 & 2.4 & & 38 & 10.0 & \\
\hline 1970-1979 & 508 & 8 & 1.6 & & 35 & 6.9 & \\
\hline 1980-1989 & 679 & 10 & 1.5 & & 46 & 6.8 & \\
\hline$>1990$ & 1020 & 18 & 1.8 & & 65 & 6.4 & \\
\hline
\end{tabular}

result in inflated risk estimates. ${ }^{31}$ However, cases were also more likely than controls to under-report exposure relative to DOM-JEM. Thus, while differential recall bias should be considered, the typical assumption regarding the direction of misclassification and the resulting inflated risk estimates was not supported by this study.

Third, risk analyses based on DOM-JEM, but not self-reports, revealed the expected associations between asbestos exposure and lung cancer risk. Those who self-reported occupational asbestos exposure in one or more jobs were not observed to be at increased risk of lung cancer. However, when DOM-JEM was used to assess exposure, exposed individuals were 90\% more likely to be diagnosed with lung cancer. The excess risk observed using the JEM is consistent with previous findings in population-based studies of occupational asbestos exposure and lung cancer risk. ${ }^{12} 16 \quad 32-37$ Furthermore, workers who were classified by DOM-JEM as exposed for more than 10 years were at increased risk of lung cancer compared with those classified as exposed for 10 or fewer years.

While the positive association between lung cancer and asbestos exposure as measured by DOM-JEM, but not self-reports, led to the conclusion that DOM-JEM may have provided a more accurate assessment approach, the extent and effect of any misclassification resulting from DOM-JEM assessment is 
Table 3 Risk estimates for asbestos exposure and lung cancer according to self-reports and DOM-JEM assessment, Greater Toronto Area, Ontario, 1997-2001

\begin{tabular}{|c|c|c|c|c|c|c|c|c|c|c|}
\hline & \multicolumn{5}{|c|}{ Self-reports* } & \multicolumn{5}{|c|}{ DOM-JEM } \\
\hline & Cases & Controls & ORt & $95 \%$ & & Cases & Controls & ORt & $95 \% \mathrm{Cl}$ & \\
\hline Never & 390 & 846 & 1.0 & & & 329 & 812 & 1.0 & & \\
\hline Ever & 29 & 48 & $0.9 \ddagger$ & 0.5 & 1.6 & 90 & 82 & 1.9 & 1.3 & 2.7 \\
\hline Low§ & & & & & & 80 & 75 & 1.9 & 1.2 & 2.6 \\
\hline Highๆ & & & & & & 10 & 7 & 2.3 & 0.8 & 6.5 \\
\hline \multicolumn{11}{|c|}{ Duration of exposure** } \\
\hline Never & 370 & 831 & 1.0 & & & 309 & 797 & 1.0 & & \\
\hline $1-10$ years & 14 & 27 & 0.9 & 0.4 & 1.8 & 44 & 53 & 1.5 & 0.9 & 2.4 \\
\hline$>10$ years & 15 & 21 & 0.9 & 0.4 & 2.0 & 46 & 29 & 2.6 & 1.5 & 4.5 \\
\hline
\end{tabular}

unknown. Since non-differential exposure misclassification is expected to bias the risk estimate towards the null, ${ }^{78}$ the positive effect estimate observed in this study may nevertheless indicate that the extent of misclassification according to DOM-JEM was smaller than that resulting from self-reports. To further examine the reliability of assessment approaches, it would be of interest to conduct a comparison of DOM-JEM and self-reports with case-by-case expert assessment. In the recent study by Offermans et al, ${ }^{13}$ DOM-JEM showed the highest level of agreement with case-by-case expert assessment of asbestos exposure in the Netherlands Cohort Study compared with two other JEMs (FINJEM and Asbestos JEM), although agreement was nonetheless moderately poor ( $\kappa 0.29$, 95\% CI 0.23 to 0.32). DOM-JEM has been compared with case-by-case expert exposure assessment (Cohen's $\kappa$ 0.17) and a population-specific JEM $(\kappa \quad 0.23)$ in a multi-centre European lung cancer casecontrol study. ${ }^{12}$ In this study, Peters et al concluded that DOM-JEM and expert assessment of asbestos exposure resulted in similar lung cancer risk estimates (OR 1.19, 95\% CI 1.05 to 1.36 and OR $1.12,95 \%$ CI 0.93 to 1.37 , respectively), while the latter approach was more time-consuming and costly.

The primary limitation of this study is the absence of a true gold standard approach for retrospective asbestos exposure assessment in population-based studies with which to compare the performance of self-reports and DOM-JEM. While case-by-case expert assessment is often favoured for retrospective exposure assessment, studies examining comparisons of expert assessment with objective measures indicate that case-by-case expert assessment should not be presumed to be the gold standard. ${ }^{1} 1230$ Additional limitations of this study should be taken into account. Participants with incomplete data collection were excluded and next-of-kin were not interviewed. If exposure increased mortality, this exclusion would have biased the effect estimates towards the null. Since this study was limited to asbestos, the observed differences between approaches may not extend to other exposures. We suspect, however, that the discordance of exposure assessments would be even greater for substances that are, or have been historically, used at lower levels, that are components of mixtures, and that are less familiar to the general working population (eg, 1,1,1-trichloroethylene). The validity of any assessment method is subject to the nature of the exposure of interest. Experts more accurately estimate exposures for commonly used agents and classes of agents compared with individual substances, ${ }^{1}$ while workers more accurately self-report exposure to substances that are easily perceptible, such as occupational noise, ${ }^{39}$ vibrations ${ }^{40}$ or odour. ${ }^{14}$ The utility of JEMs is optimised for exposures that are prevalent and occur with increased uniformity within occupational categories, since heterogeneity contributes to misclassification. ${ }^{41}$ The validity of assessments is also influenced by the questions posed to case-control study participants. Fletcher et $a l^{29}$ determined that, in interviews of Swedish construction workers, the question posed returned more accurate responses for the use of asbestos cement products than for the use of asbestos insulation products. Similarly, the question posed to participants in our study, 'In any of your jobs have you ever worked with asbestos?', may have failed to capture occupational exposures such as working in the vicinity of, but not directly with, asbestos. Workers may have been unaware of, or failed to recall or report, such exposures. Accuracy of JEMs depends on the validity of both occupation and exposure classification. While self-reports did not capture information regarding the intensity of exposure, DOM-JEM did distinguish between jobs with low and high levels of potential exposure. In a validation study of a JEM used to assess utility worker exposure to magnetic fields, the JEM effectively distinguished between workers with low and very high exposure, but introduced misclassification when intermediate categories of exposure were used. ${ }^{42}$ DOM-JEM assumes homogeneous exposure within occupational groups, which, while practical, fails to capture variations within those groups. DOM-JEM further did not capture historical changes in the prevalence of asbestos use, production processes, and the introduction and enforcement of safety measures and regulations. The discordance between approaches before 1960 may be partially attributable to poor recall and reporting by workers because of the long duration since employment and/ or overestimation of exposure by DOM-JEM, although Canada was, by 1920 , a large consumer and producer of $84 \%$ of the world's asbestos supply. ${ }^{43}$

Retrospective assessments of occupational exposures pose a significant challenge to researchers, who must carefully consider the implications of methods used to determine exposure. Our study revealed markedly different lung cancer risks associated with asbestos exposure according to each method of assessment. 
In contrast with self-reports, DOM-JEM assessment resulted in the expected excess risk estimates. When the well-established link between occupational exposure to asbestos and risk of lung cancer is considered, ${ }^{18}$ the findings of this study indicated that DOM-JEM assessment provided a more accurate measure of exposure. This study serves as a cautionary note to researchers to carefully consider the implications of the methods used to evaluate historical occupational exposures. The substantive disagreement revealed between assessment methods in this study, and the resulting impact on risk estimates indicates that results of studies using only self-reports to measure exposure should be interpreted with care, and null results should instead be considered 'inconclusive'. The findings of this study have important implications for exposure assessment in occupational health research. Detection of occupational risks, particularly at lower levels, requires valid, precise and unbiased methods of occupational exposure assessment. This is even more important in exploratory investigations of potential exposure to agents that are not yet identified or well understood.

Acknowledgements The authors gratefully acknowledge Dr Darren Brenner for his role in preparing the lung cancer case-control dataset for analysis and for providing his expertise relating to this study.

Contributors JSH and PAD were responsible for the conception and design of the study. RV, SP and HK developed the job-exposure matrix used in this analysis and conducted the linkage of the DOM-JEM to the work histories in the lung cancer case-control dataset. JRM provided the lung cancer case-control dataset. JSH carried out the data managment, analysis and preparation of the first draft of the manuscript. PAD, RV, SP, HK and JRM contributed to the interpretation of data and provided critical revisions to the intellectual content of the manuscript. All authors provided final approval of the version to be published.

\section{Competing interests None.}

Provenance and peer review Not commissioned; externally peer reviewed.

\section{REFERENCES}

1 Teschke K, Olshan AF, Daniels JL, et al. Occupational exposure assessment in case-control studies: opportunities for improvement [with Commentary]. Occup Environ Med 2002; 59:575-94.

2 Donnay C. Under-estimation of self-reported occupational exposure by questionnaire in hospital workers. Occup Environ Med 2011;68:611-17.

3 Coughlin SS. Recall bias in epidemiologic studies. J Clin Epidemiol 1990;43:87-91.

4 Delclos GL, Gimeno D, Arif AA, et al. Occupational exposures and asthma in health-care workers: comparison of self-reports with a workplace-specific job exposure matrix. Am J Epidemiol 2009;169:581-7.

5 Quinian PJ, Earnest G, Eisner MD, et al. Performance of self-reported occupational exposure compared to a job-exposure matrix approach in asthma and chronic rhinitis. Occup Environ Med 2009;66:154-60.

6 Févotte J, Dananché B, Delabre L, et al. Matgéné: a program to develop job-exposure matrices in the general population in France. Ann Occup Hyg 2011:55:865-78.

7 Kauppinen T. Assessment of exposure in occupational epidemiology. Scand J Work Environ Health 1994;20:19-29.

8 Hoar SK, Morrison AS, Cole P, et al. An occupation and exposure linkage system for the study of occupational carcinogenesis. J Occup Med 1980;22:722-6.

9 Stewart WF, Stewart PA. Occupational case-control studies: I. Collecting information on work histories and work-related exposures. Am J Ind Med 1994;26:297-312.

10 Siemiatycki J, Dewar R, Richardson L. Costs and statistical power associated with five methods of collecting occupation exposure information for population-based case-control studies. Int J Epidemiol 1989;130:1236-46.

11 Coughlin SS, Chiazze LJ. Job-exposure matrices in epidemiologic research and medical surveillance. Occup Med 1990;5:633-46.

12 Peters $\mathrm{S}$, Vermeulen R, Cassidy $A$, et al. Comparison of exposure assessment methods for occupational carcinogens in a multi-centre lung cancer case-control study. Occup Environ Med 2011;68:148-53.

13 Offermans NSM, Vermeulen R, Burdorf $A$, et al. Comparison of expert and job-exposure matrix-based retrospective exposure assessment of occupational carcinogens in the Netherlands Cohort Study. Occup Environ Med 2012;68:745-51.

14 Olsson AC, Gustavsson P, Kromhout $\mathrm{H}$, et al. Exposure to diesel motor exhaust and lung cancer risk in a pooled analysis from case-control studies in Europe and Canada. Am J Respir Med 2011;183:941-8.
15 Peters $\mathrm{S}$, Kromhout $\mathrm{H}$, Olsson $\mathrm{AC}$, et al. Occupational exposure to organic dust increases lung cancer risk in the general population. Thorax 2012;67:111-16.

16 De Matteis S, Consonni D, Lubin JH, et al. Impact of occupational carcinogens on lung cancer risk in a general population. Int/ J Epidemiol 2012;41:711-21.

17 Brenner D, Hung R, Tsao M, et al. Lung cancer risk in never-smokers: a population-based case-control study of epidemiologic risk factors. BMC Cancer 2010;10:285.

18 Straif K, Benbrahim-Tallaa L, Baan R, et al. A review of human carcinogens-Part C: metals, arsenic, dusts, and fibres. Lancet Oncol 2009;10:453-4.

19 Lenters V, Vermeulen R, Dogger $\mathrm{S}$, et al. A meta-analysis of asbestos and lung cancer: is better quality exposure assessment associated with steeper slopes of the exposure-response relationships? Environ Health Perspect 2011;119: 1547-55.

20 Kromhout $H$, Heedrik D, Dalderup LM, et al. Performance of two general job-exposure matrices in a study of lung cancer morbidity in the Zutphen cohort. Am J Epidemiol 1992;136:698-711.

21 Adegoke OJ, Blair A, Ou Shu X, et al. Agreement of job-exposure matrix (JEM) assessed exposure and self-reported exposure among adult leukemia patients and controls in Shanghai. Am J Ind Med 2004;45:281-8.

22 de Vocht F, Zock JP, Kromhout $H$, et al. Comparison of self-reported occupational exposure with a job exposure matrix in an international community- based study on asthma. Am J Ind Med 2005;47:434-42.

23 World Health Organization. International classification of diseases for oncology -3. Geneva: World Health Organization, 2000. http://www.who.int/classifications/icd/ adaptations/oncology/en/index.html (accessed 24 Jun 2013).

24 Fleiss JL, Levin B, Paik MC. Statistical methods for rates and proportions. 3rd edn. New York: John Wiley \& Sons, Inc, 2003:604.

25 Holmes E, Garshick E. The reproducibility of the self-report of occupational exposure to asbestos and dust. J Occup Med 1991;33:134-8.

26 Svendsen K, Hilt B. The agreement between workers and within workers in regard to occupational exposure to mercury in dental practice assessed from a questionnaire and an interview. J Occup Med Toxicol 2011;6:8.

27 Tielemans E, Heederik D, Burdorf A, et al. Assessment of occupational exposures in a general population: comparison of different methods. Occup Environ Med 1999:56:145-51

28 Ahrens W, Jockel KH, Brochard P, et al. Retrospective assessment of asbestos exposure -I. Case-control analysis in a study of lung cancer: efficiency of job-specific questionnaires and job exposure matrices. Int J Epidemiol 1993;22:S83-95.

29 Fletcher AC, Engholm G, Englund A. The risk of lung cancer from asbestos among Swedish construction workers: self-reported exposure and a job exposure matrix compared. Int/ J Epidemiol 1993;22:S29-35.

30 McGuire V, Nelson LM, Koepsell TD, et al. Assessment of occupational exposures in community-based case-control studies. Annu Rev Public Health 1998;19:35-53.

31 Barry D. Differential recall bias and spurious associations in case/control studies. Statist Med 1996;15:2603-16.

32 Coggon D, Pannett B, Acheson E. Use of job-exposure matrix in an occupational analysis of lung and bladder cancers on the basis of death certificates. J Natl Cancer Inst 1984;72:61-5.

33 Bovenzi M, Stanta G, Antiga G, et al. Occupational exposure and lung cancer risk in a coastal area of Northeastern Italy. Int Arch Occup Environ Heath 1993;65:35-41.

34 Van Loon AJ, Kant IJ, Swaen GM, et al. Occupational exposure to carcinogens and risk of lung cancer: results from the Netherlands cohort study. Occup Environ Med 1997;54:817-24.

35 Albin M, Magnani C, Krstev S, et al. Asbestos and cancer: an overview of current trends in Europe. Environ Health Perspect 1999;107:S289-98.

36 Gustavsson $\mathrm{P}$, Jakobsson $\mathrm{R}$, Nyberg $\mathrm{F}$, et al. Occupational exposure and lung cancer risk: a population-based case-referent study in Sweden. Am J Epidemiol 2000;152:32-40.

37 Pintos J, Parent M, Rousseau M, et al. Occupational exposure to asbestos and man-made vitreous fibers, and risk of lung cancer: evidence from two case-control studies in Montreal, Canada. J Occup Environ Med 2008;50:1273-81.

38 Armstrong BG. Methodology: effect of measurement error on epidemiological studies of environmental and occupational exposures. Occup Environ Med 1998:55:651-6.

39 Schlaefer K, Schlehofer B, Schuz J. Validity of self-reported occupational noise exposure. Eur J Epidemiol 2009;24:469-75.

40 Palmer KT, Haward B, Griffin MJ, et al. Validity of self-reported occupational exposures to hand transmitted and whole body vibration. Occup Environ Med 2000;57:237-41.

41 Committee on Human Health Risks of Trichloroethylene. Assessing the human health risks of trichloroethylene. Washington, DC: The National Academies Press, 2006:37-40.

42 Johansen C, Raaschou-Nielsen 0, Skotte J, et al. Validation of a job-exposure matrix for assessment of utility worker exposure to magnetic fields. App/ Occup Environ Hyg 2002;17:304-10.

43 Virta RL. Worldwide asbestos supply and consumption trends from 1900 through 2003:U.S. Geological Survey Circular 1298. http://pubs.usgs.gov/circ/2006/1298/ c1298.pdf (accessed 25 Sep 2013). 
A comparison of exposure assessment approaches: lung cancer and occupational asbestos exposure in a population-based case-control study

Jill S Hardt, Roel Vermeulen, Susan Peters, Hans Kromhout, John R McLaughlin and Paul A Demers

Occup Environ Med 2014 71: 282-288 originally published online December 11, 2013

doi: 10.1136/oemed-2013-101735

Updated information and services can be found at:

http://oem.bmj.com/content/71/4/282

These include:

References This article cites 39 articles, 16 of which you can access for free at: http://oem.bmj.com/content/71/4/282\#BIBL

Email alerting Receive free email alerts when new articles cite this article. Sign up in the service box at the top right corner of the online article.

Topic Articles on similar topics can be found in the following collections Collections

Asbestos (58)

Other exposures (823)

\section{Notes}

To request permissions go to:

http://group.bmj.com/group/rights-licensing/permissions

To order reprints go to:

http://journals.bmj.com/cgi/reprintform

To subscribe to BMJ go to:

http://group.bmj.com/subscribe/ 